\title{
Kanola, Aspir ve Atık Yağlardan Elde Edilen Biyodizelin Motor Performans ve Egzoz Emisyonlarina Etkisi
}

\author{
Süleyman Şimşek ${ }^{1 *}$, Hatice Şimşek ${ }^{2}$, Onur Kaya ${ }^{3}$ \\ 1* İstanbul Aydın Üniversitesi, Mühendislik Fakültesi, Makine Mühendisliği Bölümü, İstanbul, Türkiye, (ORCID: 0000-0002-0593-8036), \\ suleymansimsek@aydin.edu.tr
}

${ }^{2}$ Tekirdağ Namık Üniversitesi, Teknik Bilimler Meslek Yüksekokulu, Makine ve Metal Teknolojileri Bölümü, İstanbul, Türkiye (ORCID: 0000-0003-0041-3406), h.simsek@nku.edu.tr

${ }^{3}$ İstanbul Aydın Üniversitesi, Fen Bilimleri Fakültesi, Makine Mühendisliği Bölümü, İstanbul, Türkiye (ORCID: 0000-0002-2259-9152), onurkaya8@stu.aydin.edu.tr

(Uluslararası Araştırma-Geliştirme ve Tasarım Konferansı - 15-18 Aralık 2021)

(DOI: 10.31590/ejosat.1045568)

ATIF/REFERENCE: Şimşek, S., Şimşek, H. \& Kaya, O. (2021). Kanola, Aspir ve Atık Yağlardan Elde Edilen Biyodizelin Motor Performans ve Egzoz Emisyonlarina Etkisi. Avrupa Bilim ve Teknoloji Dergisi, (32), 577-582.

\section{$\ddot{O} \mathbf{z}$}

Dünyada enerji ve petrol kullanımı gün geçtikçe artmaktadır. Bu sebeple hava kirliliğinin enerji kullanımına paralel olarak yükselmesi, insanların yaşam standartlarını olumsuz yönde etkilemektedir. Dünyadaki enerji gereksinimlerinin \%80’i petrol, kömür, doğalgaz gibi fosil yakıtlarla karşılanmaktadır. Fosil yakıtların tükenmesi, artan enerji talepleri ve katı emisyon normları, enerji kaynağı ve talep arasındaki boşluğu azaltabilecek motor uygulamaları için biyodizel gibi alternatif yakıtlara ihtiyaç duyulmaktadır. Biyodizel taşınabilir, doğada yenilenebilir ve biyolojik olarak parçalanabilir. Birçok doğal hammadde kaynağından elde edilir ve biyodizel üretimi için tahmini 300 ürün bulunmaktadır. Bu çalışmada, biyodizel kanola, aspir ve atık yağlardan elde edilen biyodizel kullanılmıştır. Yapılan deneyler sonucunda, karışımdaki biyodizel oranı arttıkça dizel yakıtına göre özgül yakıt tüketiminde \%6.47 artış fren termik veriminde ise \%3.37 artış gözlemlenmiştir. Emisyon analiz sonuçlarında ise, karışımdaki biyodizel ile ilişkili olarak dizele kıyasla motor yük miktarına göre karbon monoksit (CO) \%18,23, hidrokarbon (HC) \%4,43 ve is \%10,95 oranında azalma olduğu, bununla birlikte azot oksit $\left(\mathrm{NO}_{\mathrm{x}}\right) \% 54,17$ ve karbon dioksit $\left(\mathrm{CO}_{2}\right) \% 26,92$ oranında motor yük miktarına göre artış göstererek kararlı bir yapı sergilemiştir.

\section{The Effect of Biodiesel from Canola, Safflower and Waste Oils on Engine Performance and Exhaust Emissions}

\begin{abstract}
The use of energy and oil in the world is increasing day by day. For this reason, the increase in air pollution in parallel with energy use affects people's living standards negatively. $80 \%$ of the world's energy needs are met by fossil fuels such as oil, coal and natural gas. With the depletion of fossil fuels, increasing energy demands and strict emission norms, alternative fuels such as biodiesel are needed for engine applications that can reduce the gap between energy source and demand. Biodiesels are portable and biodegradable, renewable in nature. It is obtained from many natural raw material sources and there are approximately 300 products for biodiesel production. In this study, biodiesel obtained from biodiesel canola, safflower and waste oils was used. As a result of the experiments, as the biodiesel ratio in the mixture increased, it was observed that the specific fuel consumption increased by $6.47 \%$ and the brake
\end{abstract}

\footnotetext{
*Sorumlu Yazar: onurkaya8@stu.aydin.edu.tr
} 
thermal efficiency increased by $3.37 \%$ compared to diesel fuel. In the emission analysis results, it was found that carbon monoxide (CO) decreased by $18.23 \%$, hydrocarbon (HC) by $4.43 \%$ and is $10.95 \%$ compared to the amount of engine load in relation to the biodiesel in the mixture, however nitrogen oxide (NOx) ) showed a stable structure by increasing 54.17\% and carbon dioxide (CO2) by $26.92 \%$ according to the amount of engine load.

Keywords: Biodiesel, Waste Oil, Diesel Engine, Exhaust Emissions

\section{Giriş}

Dünyada enerji ve petrol kullanımının yükselmesi, rezervlerin tükenme endişesini artırmaktadır. Uzun yıllardır petrol, doğal gaz ve kömür gibi fosil yakıtlar küresel olarak başlıca enerji kaynakları olarak kabul edilmektedir. Ancak, bu enerji kaynakları yenilenemez olduğundan ve hızlı nüfus artışından kaynaklanan, sürekli artmakta olan talep nedeniyle yakında tükenmeleri muhtemeldir. Ayrıca fosil yakıtların aşırı kullanımı çevre üzerinde olumsuz etkilere neden olmaktadır. Sonuç olarak, çevresel bozulmayı azaltmak için emisyon düzenlemeleri giderek daha fazla güçlendirilmektedir. $\mathrm{Bu}$ nedenle, daha temiz ve ekonomik olarak uygulanabilir yenilenebilir enerji kaynaklarına duyulan ihtiyaç, araştırmacıları yeni kaynaklar aramaya yöneltmiştir(Tesfa, Gu, Mishra, \& Ball, 2014). Zararlı fosil yakitlarına $\mathrm{CO}, \mathrm{NO}_{\mathrm{x}}, \mathrm{CO}_{2}$ ve $\mathrm{HC}$ ve benzeri gazlar gösterilebilir. $\mathrm{Bu}$ yüzden petrol esaslı yakıtların yerine hava kirliliğine etkisi daha düşük olan, fosil yakıtların yerine geçebilecek alternatif yakıtlar araştırılmaktadır(Er, 2009). Bunlara örnek olarak biyodizel yakıtlar gösterilebilir. Biyodizelin alternatif yakıt olarak tercih edilmesinin nedeni günümüzde kullanılan fosil yakıtlarına göre yenilenebilir olması ve egzoz emisyonunda daha az hidrokarbon(HC), monoksit(CO), kükürt $\operatorname{dioksit}\left(\mathrm{SO}_{2}\right)$, civa(HG) ve partikül içermesidir(Tillem, 2005). Biyodizelin büyük ölçeklerde üretilmesi halinde tarımsal hammaddeler için ek gelir kaynakları ve yatırımları elde edilebilmesi, fosil yakıtlar için ise fiyat rekabeti yaratması, fosil yakıtların ücretlerinde gerileme olması gibi sonuçlar biyodizelin tercih edilme sebepleri arasındadır(Szulczyk \& McCarl, 2010).

Biyodizel üretimi için hammadde olarak yenmeyen yağların kullanılması, gıda güvenliği ve gıda ile yakıt arasındaki tartışma ile ilgili zorlukların üstesinden geldiği için araştırmaların daha fazla ilgisini çekmiştir. Ayrıca, yağın fiyatı diğer kaynaklardan gelen yeni yağa kıyasla önemli ölçüde düşük olduğundan, atık yemeklik yağlar daha ucuz bir biyodizel hammaddesi olarak kabul edilir(Attia \& Hassaneen, 2016). Atık yemeklik yağın kullanımıyla ilgili ek bir fayda, bir enerji kaynağı olarak geri dönüştürülmesinin en iyi bertaraf yöntemini sunmasıdır. Atık yemeklik yağlar, geleneksel dizel yakıta göre daha yüksek viskoziteye sahiptir ve bu nedenle doğrudan dizel motorda kullanılamaz (Şen, 2012). Daha yüksek viskozite, daha büyük moleküler kütle ve kimyasal yapıdan kaynaklanır(Karmakar, Karmakar, \& Mukherjee, 2010). Dizel motorun mucidi "Rudolf Diesel" tasarladığ 1 motorunu 1898 yılında Paris’teki Dünya sergisinde fistık yağı ile çalıştırarak tanıtmıştır. Ayrıca "Rudolf Diesel" bir açıklamasında "Dizel motorlar bitkisel yağlarla çalıştırılabilir ki, bu durum ülkelerin tarımını geliştirmelerine yardımcı olacaktır" demiştir(Kafadar, 2010)

Biyodizel, sera gazı emisyonlarını azalttığı ve son yıllarda artan çevre bilinci nedeniyle giderek daha önemli hale gelmektedir. Bitkisel yağlar ve bunların dizel yakıtı ile karışımları yakıtların bulutlanma noktası, viskozite, kalorifik değer ve setan sayısı gibi fiziksel ve kimyasal özelliklerini değiştirir(Simsek,
2020). Örneğin yüksek setan sayıları dizel vuruntusunu azaltır, soğuk hava koşullarında motorun çalışmasını kolaylaştırır ve motor ömrünü uzatır. Bazı çalışmalarda biyodizel yakıtın motor gücü ve momentinde hafif bir artışa neden olduğu ve bu artışın biyodizel yakıtındaki oksijen içeriğinin zengin alev bölgesinde yanmasından kaynaklandığı belirtilmiştir(Simsek, 2020). Diğer çalışmalarda ise biyodizelin dizel yakıta göre bileşiminde \%9-13 oranlarında oksijen bulunması ve daha düşük kalorifik değer nedeniyle motor gücünde ve torkunda hafif bir azalmaya neden olduğu belirtilmiştir(Demirbas \& Balat, 2006).

Bitkisel yağların yakıt özelliklerinin iyileştirilmesine yönelik çalışmalar, öncelikle yağların viskozitesini düşürmeye yöneliktir(Alptekin \& Çanakçı, 2006). Viskozitenin düşürülmesi için kullanılan ısıl ve kimyasal yöntemler vardır(Ilgazlı, 2010). Kimyasal yöntem ile seyreltme, mikroemülsiyon, proliz(ayrıştırma) ve transesterifikasyon yöntemleri ile iyileştirme prosedürleri vardır(Ilgazlı, 2010).

\section{Tablo 1. Bitkisel ve ya hayvansal yağların biyodizel} aşamaları.

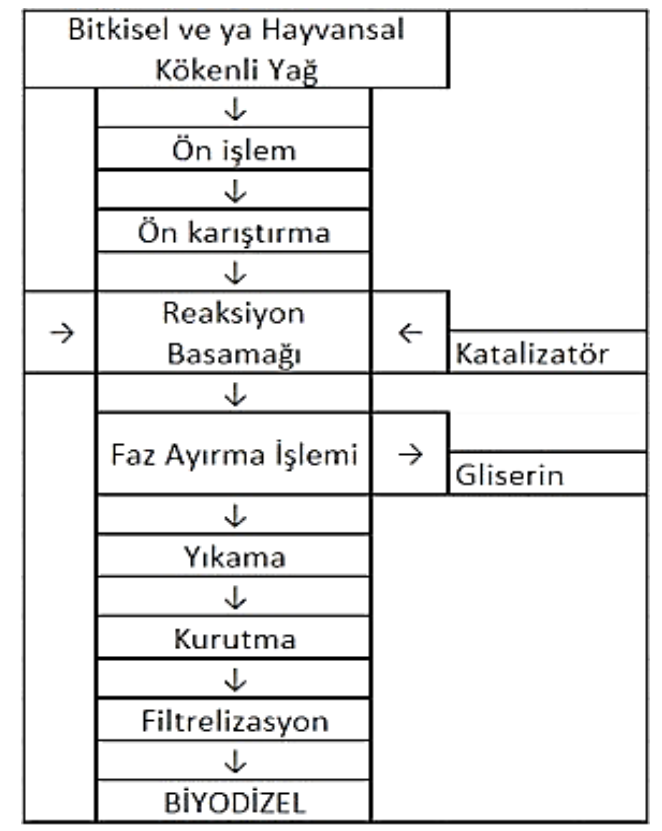

Nanoparçacıklar, 10-1000 nm aralığında bir boyuta sahip partikül dispersiyonları veya katı partiküller olarak tanımlanır(Li et al., 2009). Setan sayısını artırmanın ve zararlı egzoz emisyonlarını azaltmanın yöntemlerinden biri biyodizele katkı maddesi, nanoparçacıkların eklenmesidir(Şimşek, 2020).

\section{Materyal ve Metot}

Kanola, aspir ve atık bitkisel yağlardan elde edilen biyodizelin eşit oranlarda karıştırılmasıyla biyodizel kombinasyonu elde edilmiştir. Deneyler de bu karışım üzerinden hazırlanmıştır. Deneyde kullanılan nanoparçacık oranları, Testlerde kullanılan biyodizel, dizel yakıtının analizleri TÜBITTAK Marmara Araştırma Merkezi enerji ve kimya laboratuvarında TS EN 14214 standardına göre doğrulanmıştır. 
Yapılan deneysel çalışmada $3000 \mathrm{rpm}$ sabit devirli, hava soğutmalı, dört zamanlı dizel motor kullanılmıştır. Motorun özellikleri ve deneylerde kullanılan jeneratöra ait özellikler Tablo 2'de verilmiştir. Motorun performansı ve egzoz emisyon değerlerinin ölçümlerinden önce motor çalışma sıcaklığına ulaşana kadar çalıştırılmıştır. Motora sırasıyla 1000, 1500, 2000, 2500 ve 3000 watt'lık güce sahip halojen lambalar ile yüklenerek testler yapılmıştır. Test motoru biyodizel/dizel yakıt karışımları ile belirlenen motor yüklerinde çalıştırılarak performans ve emisyon değerleri hesaplanmıştır. Bir dizel motorda alternatif yakıt olarak transesterifikasyon ile üretilen biyodizelin kullanıldı̆̆ kanola, aspir ve atık bitkisel yağların $\mathrm{CO} 2, \mathrm{NOx}$ ve duman egzoz emisyonları ölçülmüş ve kaydedilmiştir. Şekil 1, test aparatının şematik bir gösterimini göstermektedir.

Tablo 2. Deney Motorunun Özellikleri

\begin{tabular}{c|c}
\hline \multicolumn{2}{c}{ Motorun Özellikleri } \\
\hline Marka & Katana \\
\hline Model & M $178 \mathrm{FE}$ \\
\hline Çap ve Strok & 78 X $62 \mathrm{~cm}$ \\
\hline Silindir Hacmi & $296 \mathrm{~cm}^{3}$ \\
\hline Maksimum Beygir Gücü & $6,7 \mathrm{Beygir}$ \\
\hline Motor Hızı & $3000 \mathrm{rpm}$ \\
\hline Elektrik Sistemi & $12 \mathrm{~V}-36 \mathrm{Ah}$ \\
\hline Yakıt & Dizel \\
\hline Yakıt Tankı Kapasitesi & $11 \mathrm{Lt}$ \\
\hline Yağ Tankı Kapasitesi & $1.1 \mathrm{Lt}$ \\
\hline
\end{tabular}

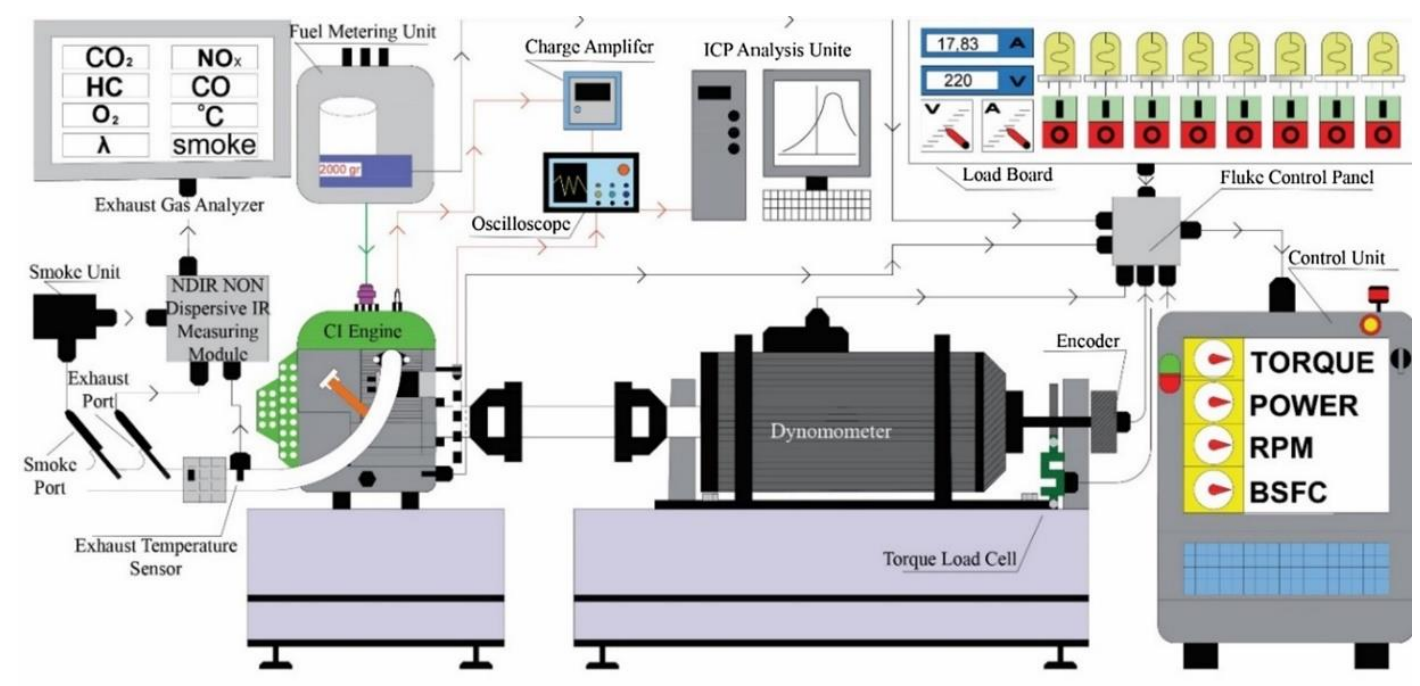

Şekil 1. Deney ortamının grafik resmi\{Simsek, 2020 \#11\}

\section{Araştırma Sonuçları ve Tartışma}

\subsection{Araştırma Sonuçları}

Kanola, aspir ve atık yağların transesterifikasyonu ile elde edilen biyodizelin kullanıldığı belirtilen dizel motor için fren 1 sıl verimi, özgül yakıt tüketimi ve egzoz emisyonları $\left(\mathrm{CO}, \mathrm{HC}, \mathrm{CO}_{2}\right.$, $\mathrm{NO}_{\mathrm{x}}$ ) ölçülerek kaydedilmiştir. $\mathrm{O}_{2}, \mathrm{HC}, \mathrm{CO}_{2}, \mathrm{CO}$ ve $\mathrm{NOx}$ emisyonlarının yanı sıra lambda değerleri, bir Bilsa MOD 2210 WINXP-K egzoz gazı emisyon analizörü kullanılarak ölçülmüştür. Emisyon analizörü Tablo 3'de gösterildiği gibi doğru bir şekilde kullanılmıştır.

Tablo 3. Egzoz gazı emisyon analizörü ile kullanılan ölçüm aralıkları

\begin{tabular}{c|c|c}
\hline Değişken & Ölçǜm Aralığı & Kesinlik \\
\hline$C O$ & $\% 0-10.0$ hacmen & $\% 0,00$ \\
\hline Lambda & $0,5-2.00$ & 0.001 \\
\hline
\end{tabular}

\begin{tabular}{c|c|c}
$\mathrm{NO}_{x}$ & $0-5000$ & $1 \mathrm{ppm}$ \\
\hline $\mathrm{O}_{2}$ & $\% 0-10$ hacmen & $\% 0.01$ \\
\hline $\mathrm{HC}$ & $0-10.000 \mathrm{ppm}$ hacmen & $1 \mathrm{ppm}$ \\
\hline $\mathrm{CO}_{2}$ & $\% 0-20.0$ hacmen & $\% 0,00$ \\
\hline $\mathrm{Hlz}$ & $0-9990$ dev/dak. & $10 \mathrm{rpm}$ \\
\hline
\end{tabular}

\subsubsection{Efektif Verim}

Motorda yanan yakıtın ne kadar faydalı işe dönüştüğünü gösteren ölçüme efektif verim denilmektedir. Yanma sonucu üretilen enerjinin çoğu yağlama, soğutma ve egzoz gazı yoluyla motordan uzaklaştırılır, ancak kalan enerji motor için güce dönüştürülür(Şimşek, Özdalyan, Saygın, \& Şimşek, 2018). 
Efektif güç aynı zamanda faydalı güç, efektif güç veya frenleme gücü olarak da adlandırılır. Bu güç, motorun gerçek gücüdür. Silindirlerde elde edilen belirtilen güçten; Motorun çalışması için gerekli kuvvetler düşüldükten sonra motorun volanından veya kasnağından ölçülen güçtür.

Efektif verimi hesaplamak için aşağıdaki denklem kullanılmaktadır;

$$
\eta=\frac{P e * 3600}{B * H u}
$$

\section{$\eta=$ Efektif Verim}

$\mathrm{P}_{\mathrm{e}}=$ Motor Gücü $(\mathrm{kW})$

$\mathrm{B}=$ Saatlik Yakıt Tüketimi (kgh)

$\mathrm{Hu}=$ Kullanılan Yakıtın Alt Isıl Değeri

Tablo 4'de BD0, BD10 ve BD20 yakıtları için efektif verim grafiği verilmiştir. BD10, BD20 yakıtlarının fren termik verimleri BD0 yakıtı ile karşılaştırıldığında ortalama olarak sırasıyla $\% 4,20$ ve $\% 3,37$ oranında artış tespit edilmiştir.

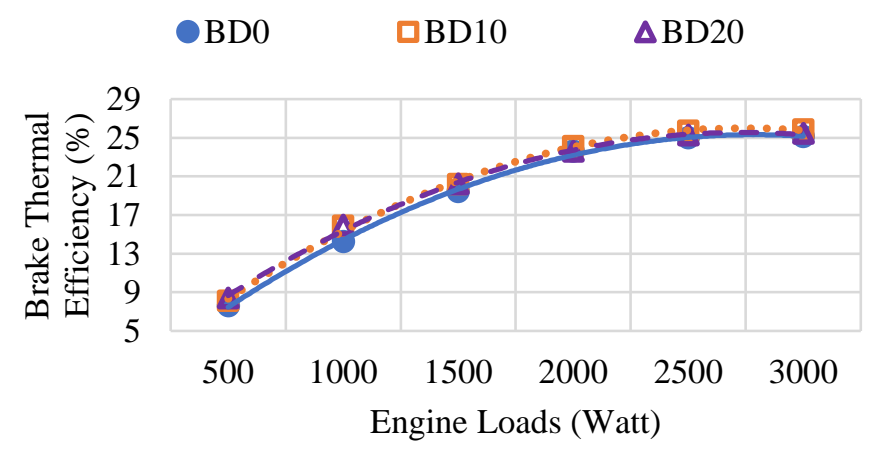

Tablo 4. Biyodizel yakıt karışımlarının efektif veriminin grafiği.

\subsection{2. Özgül Yakıt Tüketimi}

Motorda kullanılan yakıt 1S1 enerjisine dönüşürken dönüştürülen enerjinin krank miline etkisini gösteren değere özgül yakıt tüketimi denir. Yani birim güç başına kullanılan yakıt miktarıdır(Samet Çat, Uslu, Çelik, \& Özdalyan, 2018).

Özgül yakıt tüketimini hesaplamak için aşağıdaki denklem kullanılmaktadır;

$$
b e=\frac{B * 1000}{P_{\mathrm{e}}}
$$

be $=$ Özgül Yakıt Tüketimi $(\mathrm{g} / \mathrm{kWh})$

$\mathrm{B}=$ Saatlik Yakıt Tüketimi (kgh)

$\mathrm{P}_{\mathrm{e}}=$ Motor Gücü $(\mathrm{kW})$

Tablo 5'de BD0, BD10 ve BD20 yakıtları için özgül yakıt tüketimi grafiği verilmiştir.
BD10, BD20 yakıtlarının özgül yakıt tüketimleri BD0 yakıtı ile karşılaştırıldığında ortalama olarak sırasıyla $\% 3,79$ ve $\% 6,47$ oranında artış tespit edilmiştir

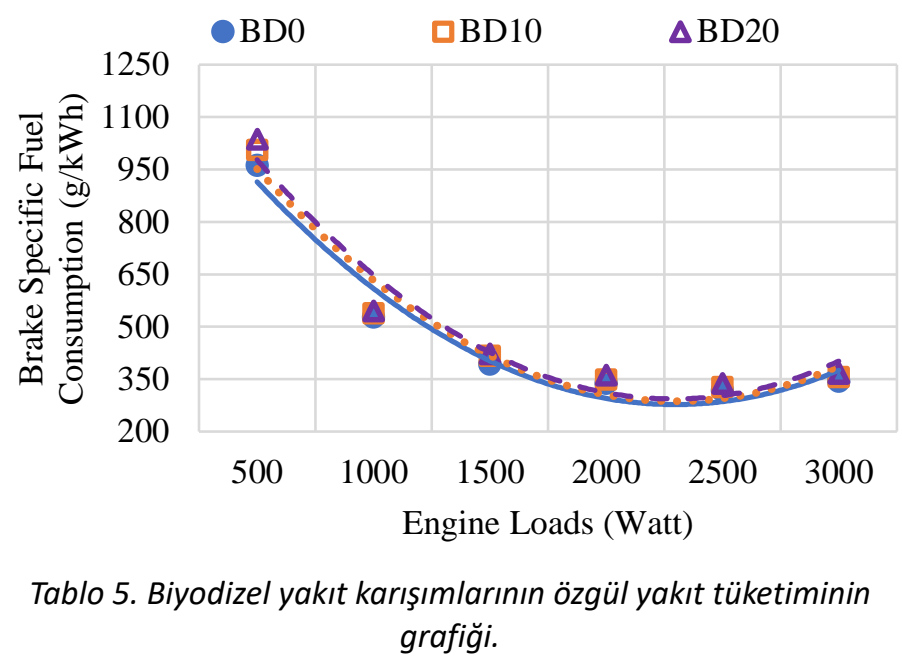

\subsubsection{Hidrokarbon $(\mathrm{HC})$ emisyonlart}

Tablo 6'da BD0, BD10 ve BD20 yakıtları için HC emisyonu grafiği verilmiştir. $\mathrm{BD} 10, \mathrm{BD} 20$ yakıtlarını $\mathrm{HC}$ emisyonlar $\mathrm{BD} 0$ yakıtı ile karşılaştırıldı ı̆ında ortalama olarak sırasıyla \%1,29 ve $\% 4,43$ oranında artış tespit edilmişsir

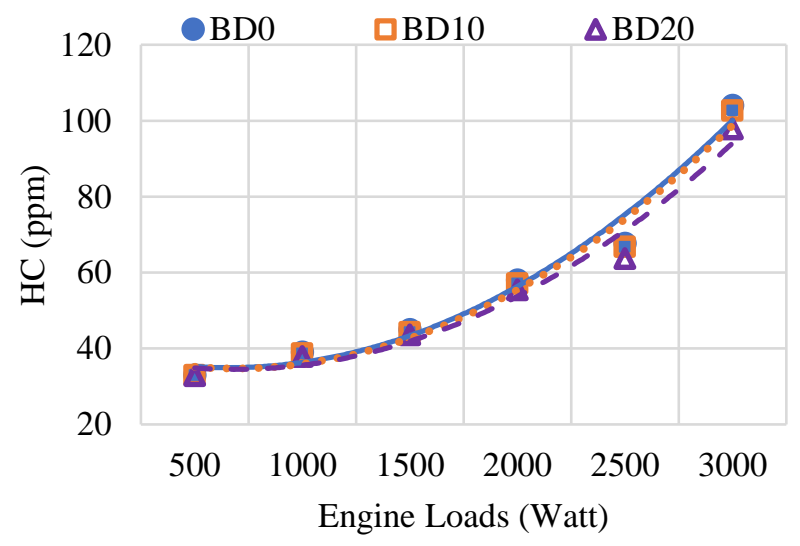

Tablo 6. Motor yüküne göre HC emisyon grafiği

\subsubsection{Nitrojen oksit(NOx) emisyonlart}

İçten yanmalı motorlarda NOx emisyonu havadaki nitrojenin yüksek sıcaklıklarda oksijene tepki vermesinden oluşmaktadır. Tablo 7'de BD0, BD10 ve BD20 yakıtları için NOx emisyonu verilmiştir. BD10, BD20 yakıtlarının $\mathrm{NO}_{x} \mathrm{BD} 0$ yakıtı ile karşılaştırıldığında ortalama olarak sırasıyla $\% 45,63$ ve $\% 54,17$ oranında artış tespit edilmiştir 


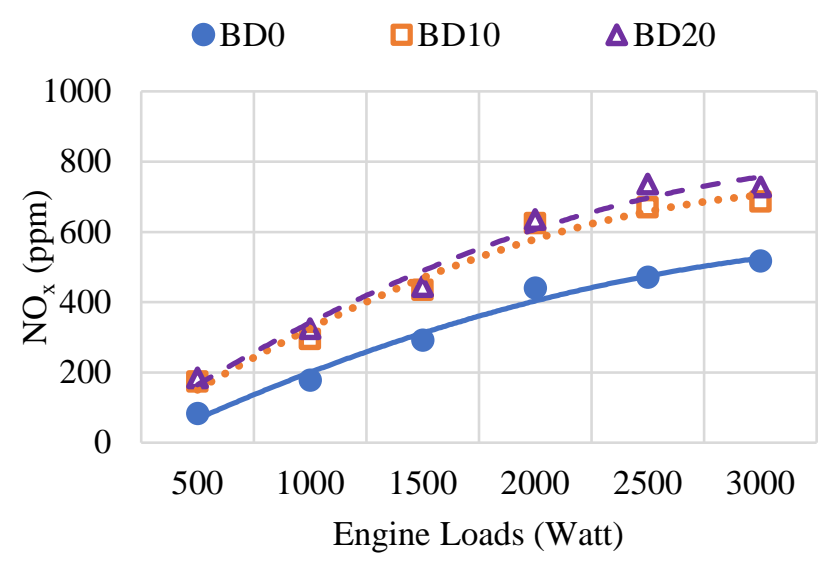

Tablo 7. Motor yüküne göre NOx emisyon grafiği.

\subsubsection{Karbondioksit $\left(\mathrm{CO}_{2}\right)$ emisyonlart}

Tablo 8'de BD0, BD10 ve BD20 yakıtları için $\mathrm{CO}_{2}$ emisyonu grafiği verilmiştir. BD10, BD20 yakıtlarının $\mathrm{CO}_{2}$ emisyonu BD0 yakıtı ile karşılaştırıldığında ortalama olarak sırasıyla $\% 4,83$ ve \%26,92 oranında artış tespit edilmiştir Şekilde görüldüğü gibi artan motor yükü ile $\mathrm{CO}_{2}$ emisyonu artmıştır ve B20 karışımları dizel yakıta göre daha yüksek $\mathrm{CO}_{2}$ emisyon değerlerine ulaşmıştır. Motor yükünün $\mathrm{CO}_{2}$ ile paralel emisyon değerlerinin artması BD20 karışımlarında yakıtın buharlaşma hızı ile setan sayısının artmasının sonucudur(Baghban, Kardani, \& Mohammadi, 2018).

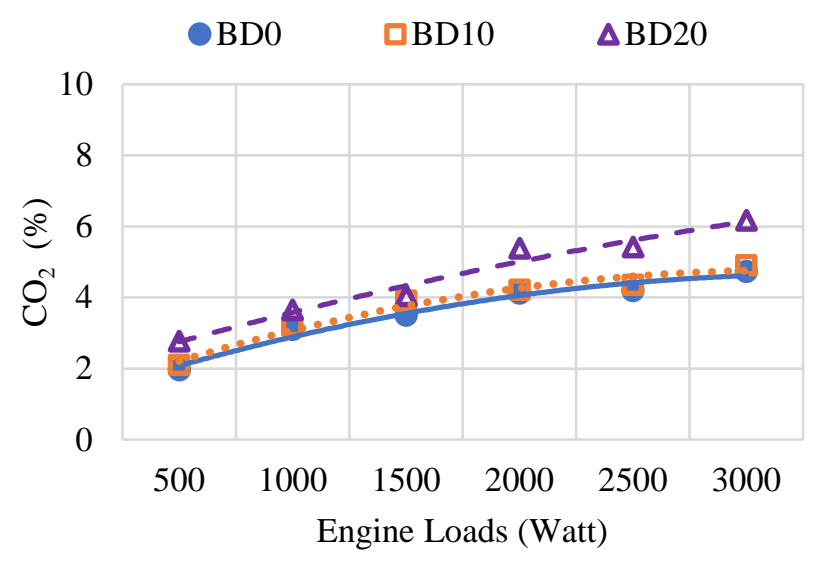

Tablo 8. Motor yüküne göre $\mathrm{CO}_{2}$ emisyon grafiğ $i$

\subsubsection{Karbon monoksit (CO) emisyonlart}

İçten yanmalı motorlardan kaynaklanan tüm emisyonlar, yakı1t türü, yanma odası tasarımı, atomizasyon hızı, motor hızı ve hava yakıt oranı gibi motor çalışma parametrelerini etkiler. Tablo 9' da $\mathrm{BD} 0, \mathrm{BD} 10$ ve $\mathrm{BD} 20$ yakıtları için $\mathrm{CO}$ emisyonu grafiği verilmiştir. BD10, BD20 yakıtlarının CO emisyonu BD0 yakıtı ile karşılaştırıldığında ortalama olarak sırasıyla \%13,30 ve \%18,23 oranında artış tespit edilmiştir

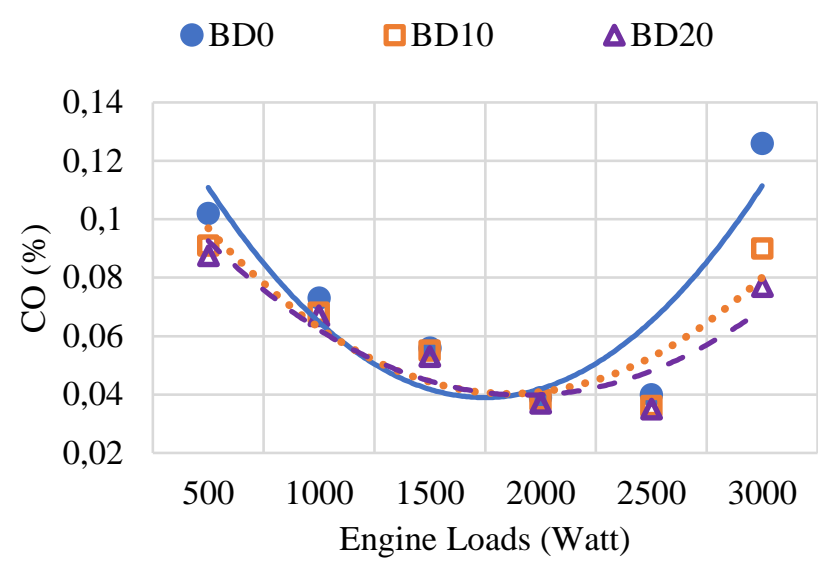

Tablo 9. Motor yüküne göre CO emisyon grafiği

\section{Sonuç}

Biyodizel kullanıldığında motorine kıyasla $\mathrm{CO}$ ve $\mathrm{HC}$ emisyonlarında azalma meydana gelmiştir. NOx emisyonunda ise artış meydana gelmiştir.

Motor deneyleri esnasında motor parçaları üzerinde herhangi bir olumsuz durum gözlemlenmemiştir.

Biyodizelin kullanımında egzoz emisyon gaz sıcakları motorin yakıtınınkilere göre daha düşük olarak ölçülmüştür. Biyodizelin setan sayısının yüksek olması sebeiyle yanmanın genişleme periyoduna kaymadan tamamlanabilmesi sağlanmaktadır.

Biyodizelin alt 1sıl değerinin motorine göre daha düşük olması sebebiyle özgül yakıt tüketiminde BD0 yakıtına göre diğer bütün karışımlarda artış gözlemlenmiştir.

3000W Motor yükünde BD0 yakıtına oranlar BD10 ve BD20 oranlarında artış gözlemlenmiştir.

\section{Kaynakça}

Alptekin, E., \& Çanakçı, M. (2006). Biyodizel ve Türkiye'deki durumu. Mühendis ve Makine, 47(561), 57-64.

Attia, A. M., \& Hassaneen, A. E. (2016). Influence of diesel fuel blended with biodiesel produced from waste cooking oil on diesel engine performance. Fuel, 167, 316-328.

Baghban, A., Kardani, M. N., \& Mohammadi, A. H. (2018). Improved estimation of Cetane number of fatty acid methyl esters (FAMEs) based biodiesels using TLBO-NN and PSONN models. Fuel, 232, 620-631.

Demirbas, M. F., \& Balat, M. (2006). Recent advances on the production and utilization trends of bio-fuels: a global perspective. Energy Conversion and Management, 47(1516), 2371-2381.

Er, H. (2009). Pamuk yağı metil esterinin yakt olarak bir dizel taşıtında kullanımı ve taşıt performansına etkisinin araştırılması. Fen Bilimleri Enstitüsü,

Ilgazlı, Ö. (2010). Değiştirilebilir sıkıştırma oranına sahip bir sıkıştırma ateşlemeli motorda diesel-biodiesel karışımlarının motor performansına ve emisyonlarına etkisinin araştırılması.

Kafadar, A. (2010). Yağlardan biyodizel eldesine etki eden faktörlerin araştırılması. Doktora Tezi, Dicle Üniversitesi,

Karmakar, A., Karmakar, S., \& Mukherjee, S. (2010). Properties of various plants and animals feedstocks for biodiesel production. Bioresource technology, 101(19), 7201-7210. 
Li, H., Zhao, X., Ma, Y., Zhai, G., Li, L., \& Lou, H. (2009). Enhancement of gastrointestinal absorption of quercetin by solid lipid nanoparticles. Journal of Controlled Release, 133(3), 238-244.

Samet Çat, M. A., Uslu, S., Çelik, M. B., \& Özdalyan, B. (2018). DÜŞÜK GÜÇLÜ BİR DİZEL MOTORDA ATIK BIYODIZEL KULLANIMININ MOTOR PERFORMANS VE EMISYONLARINA ETKISII.

Simsek, S. (2020). Effects of biodiesel obtained from Canola, sefflower oils and waste oils on the engine performance and exhaust emissions. Fuel, 265, 117026.

Szulczyk, K. R., \& McCarl, B. A. (2010). Market penetration of biodiesel. Renewable and Sustainable Energy Reviews, 14(8), 2426-2433.

Şen, S. (2012). Hayvansal yağlardan biyodizel üretimi ve dizel motor performans ve emisyonlarına etkisinin araştırılması. Fen Bilimleri Enstitüsü,

Şimşek, S. (2020). Increasing Cetane Number of the Diesel Fuel by Fuel Additives. International Journal of Automotive Science And Technology, 4(4), 300-306.

Şimşek, S., Özdalyan, B., Saygın, H., \& Şimşek, H. (2018). İÇTEN YANMALI MOTORLARDA YAKIT OLARAK FUZEL YAĞININ ELDE EDILLMESI VE ANALIZII.

Tesfa, B., Gu, F., Mishra, R., \& Ball, A. (2014). Emission characteristics of a CI engine running with a range of biodiesel feedstocks. Energies, 7(1), 334-350.

Tillem, İ. (2005). Dizel motorlar için alternatif yakıt olarak biyodizel üretimi ve kullanımı. Pamukkale Üniversitesi Fen Bilimleri Enstitüsü, 